\title{
Abstract
}

\section{Teledermatology: Experience in Singapore}

\author{
Eugene Sern-Ting Tan, MBBS \\ National Skin Centre, Singapore, Singapore
}

\section{Corresponding Author:}

Eugene Sern-Ting Tan, MBBS

National Skin Centre

1 Mandalay Rd,

Singapore, 308205

Singapore

Phone: 6563506666

Email: eugenetan@nsc.com.sg

\section{Abstract}

Background: The COVID-19 pandemic has accelerated the development and widespread adoption of teledermatology both locally and globally. As dermatology is predominantly a visual specialty, teledermatology is particularly useful for patient care and collaboration between health care professionals.

Objective: To share lessons learned from the local experience with teledermatology in Singapore.

Methods: The main models of teledermatology are asynchronous (store-and-forward), synchronous (real-time communication), and hybrid teledermatology (mixed combination of both asynchronous and synchronous elements).

Results: During the pandemic, teledermatology has enabled suitable patients to have continued access to clinical care in the comfort of their home, while at the same time supporting safe distancing measures to mitigate exposure to and spread of SARS-CoV-2. At the National Skin Centre in Singapore, asynchronous store-and-forward teledermatology is used for telecollaboration with doctors and nurses from external health care institutions, nursing homes, and primary care clinics. A hybrid model comprising synchronous phone or video teleconsultation with the patient, together with review of recent clinical photographs submitted by the patient, is used for the remote care of selected patients with mild and/or stable dermatological conditions. There is a high diagnostic concordance of $87 \%$ between teleconsultation and in-person consultation. As not all patients are suitable for teleconsultation, preteleconsultation triage is helpful.

Conclusions: Moving forward, even as we approach a new postpandemic era, teledermatology will continue to evolve and become an integral pillar of the health care landscape.

Conflicts of Interest: None declared.

(iproc 2022;8(1):e36900) doi: $\underline{10.2196 / 36900}$

\section{KEYWORDS}

teledermatology; teleconsultation; synchronous; asynchronous; store-and-forward; hybrid; Singapore

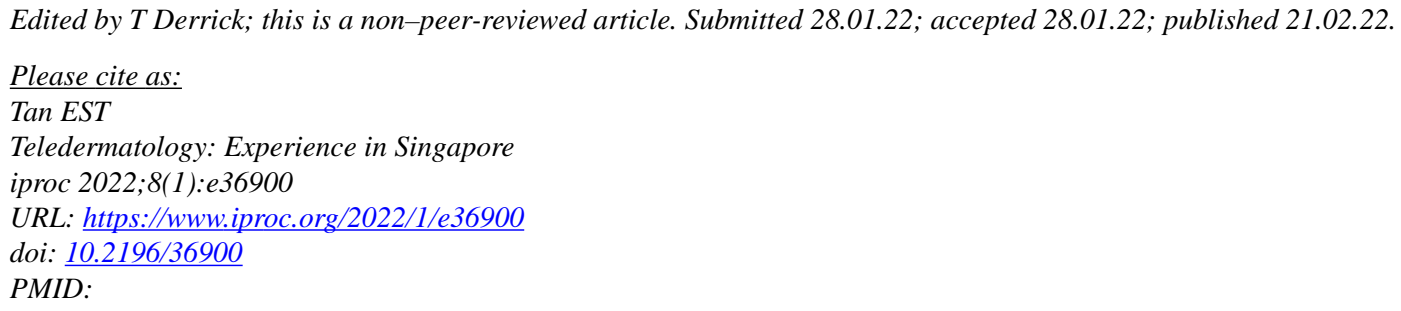


CEugene Sern-Ting Tan. Originally published in Iproceedings (https://www.iproc.org), 21.02.2022. This is an open-access article distributed under the terms of the Creative Commons Attribution License (https://creativecommons.org/licenses/by/4.0/), which permits unrestricted use, distribution, and reproduction in any medium, provided the original work, first published in Iproceedings, is properly cited. The complete bibliographic information, a link to the original publication on https://www.iproc.org/, as well as this copyright and license information must be included. 